Microbes and Health

ISSN: 2226-0153 (Print) 2305-3542 (Online)

http://journal.bsvmph.org/

Microbes and Health, December 2012, 1(2): 50-53

DOI: $10.3329 /$ mh.v1i2.14089

\title{
Immunogenicity of BAU-Bivalent Salmonella and Fowl Cholera Vaccines in Shuvra Chickens
}

\author{
Manasi Modak, Md. Mansurul Amin, Sukumar Saha* and Jayedul Hassan \\ Department of Microbiology and Hygiene, Faculty of Veterinary Science, Bangladesh Agricultural University, Mymensingh-2202, \\ Bangladesh. \\ ${ }^{*}$ Corresponding author's e-mail: sukumar94@yahoo.com
}

[Received: 11 November 2012, Revised: 29 November 2012, Accepted: 06 December 2012]

\section{A B S T R A C T}

The study was performed to investigate the immunogenicity of Salmonella and Fowl cholera vaccine prepared at BAU using Shuvra strain of chickens administered with BAU Salmonella bivalent and BAU Fowl cholera vaccines prepared by "Livestock and Poultry Vaccine Research and Production Centre", (LPVRPC). A total of 60 apparently healthy BLRI strains Shuvra were used in this study. The birds were divided into three groups, consisting of 20 birds in each group. Shuvra- A group birds were vaccinated with BAU Salmonella bivalent vaccine, Shuvra-B group birds with BAU Fowl cholera vaccines and Shuvra-C group birds were used as unvaccinated control. The birds, except the ones in group $\mathrm{C}$, were vaccinated intramuscularly $(0.5 \mathrm{ml})$ at 8 weeks of age followed by a booster dose at 12 weeks of age. Sera samples were collected on day 56, 85, 105 days and after challenge at 140 days age of birds. Secondary (booster) vaccination $(P<0.05)$ exhibited a significant level of antibody response. The antibody titre of these birds slowly descended till four weeks of challenge test. It was observed that a dependable level of immunogenicity of BAU Salmonella Bivalent and BAU Fowl cholera vaccine was observed when administered under this schedule followed in Shuvra strain of chickens.

Keywords: Shuvra, BAU Salmonella bivalent vaccine, BAU Fowl cholera vaccine, efficacy.

(C) 2012 Microbes and Health. All rights reserved

\section{Introduction}

Life and land are closely entwined in Bangladesh of which the total agriculture including livestock is a glaring example. In case of livestock, poultry has by now turned out to be close to an industry (Aklilu et al., 2008). However, there was a growing concern for a type of chicken that would be well-suited to rural Bangladesh along with increased production quality with a comparable feed conversion rate (CFR). In view of this, Bangladesh Livestock Research Institute (BLRI) after a long and strenuous research achieved a proud product with the support from Japan International Cooperation Agency (JICA) and very recently released a strain of poultry named 'Shuvra' indicating whiteness of the color of body (UNB, 2011). The new strain of chicken has, by now, been handed over to commercial poultry farm to rear and study of production factors as well as to distribute to rural areas. At this junction, the question of disease resistance and study of immunogenic capacity of birds came for discussion and scientific investigation.

Infectious diseases are a major cause of poultry death worldwide. Of the bacterial diseases causing tremendous loss of poultry, Salmonellosis and Fowl cholera are noteworthy. The former ailment is due to the pathogen Salmonella in poultry and is termed as Pullorum disease (PD) and Fowl typhoid (FT) (Shivaprasad and Barrow, 2008). Salmonellosis in poultry causes heavy economic loss of poultry rearing and the mortality rate is

To cite this article: Modak M, MM Amin, S Saha and J Hassan, 2012. Immunogenicity to BAU-Bivalent Salmonella and Fowl Cholera vaccine in Shuvra strain of chickens. Microbes Health, 1(2): 50-53. as high as $100 \%$ (Khan et al., 1998), and reduced production (Klein, 1889; Retteger, 1900) and the morbidity rate is often significantly higher than the mortality rate (Kottwitz et al., 2010). On the other hand, Pasteurellosis (Fowl cholera) is also a bacterial disease of economic importance that account for $25 \%$ to $30 \%$ chicken mortality all over Bangladesh (Choudhury et al., 1985).

A number of research programme has been carried out in the Department of Microbiology and Hygiene, BAU, Mymensingh, on the immunogenic performance of Salmonella bivalent (Ferdous, 2008; Khatun, 2011). But reports on immune response of newly developed Shuvra were very limited. This investigation is a primary one on the immune response of this type of birds following vaccination with Salmonella bivalent and Fowl cholera vaccines prepared by "Livestock and Poultry Vaccine Research and Production Centre", (LPVRPC) of the Department of Microbiology and Hygiene, Bangladesh Agricultural University (BAU), Mymensingh.

\section{Materials and Methods}

Study location and duration

The present research was carried out at the Department of Microbiology and Hygiene, BAU, Mymensingh during the period of May, 2011 to April, 2012.

Vaccines used

Salmonella bivalent and Fowl cholera vaccines produced by LPVRPC, BAU, Mymensingh were used in this study. 
Experimental chickens and laboratory animals

A total number of 60 aged eight (8) weeks of newly developed strain of chicken named Shuvra were used for this experiment. These birds were obtained as day-old chicks with the courtesy of Bangladesh Livestock Research and Institute (BLRI). A total of 74 healthy suckling day-old mice were collected for the determination of $\mathrm{LD}_{50}$ and safety test of the vaccines. A total of 4 apparently healthy adult rabbits were used for the collection of sera for PHA test.

\section{$\mathbf{L D}_{50}$ determination in mice}

S. gallinarum, S. pullorum and $P$. multocida were cultured separately in nutrient broth overnight at $37^{\circ} \mathrm{C}$ in a shaker incubator and after 12 hours growth, they were centrifuged at $1500 \mathrm{rpm}$ for 5 minutes. The supernatant was decanted off, and the sediment was washed thrice with PBS. The pellet was dissolved with sufficient amount of PBS and measured the OD value at $550 \mathrm{~nm}$ and adjust the $\mathrm{OD}$ value at 2.83. $250 \mu \mathrm{l}$ and 100 $\mu 1,50 \mu 1$ and $25 \mu 1$ of bacterial suspension was injected intraperitonially respectively in 4 groups of mice, each group containing 8 and same amount of PBS was injected in each corresponding control group. Death pattern was observed until 10 days. A 10 fold dilution was made and spread on NA media for CFU count, $P$. multocida $250 \mu 1$ of $2.43 \times 10^{8} \mathrm{CFU} / \mathrm{ml}$, Salmonella gallinarum $8.6 \times 10^{13} \mathrm{CFU} / \mathrm{ml}$ and Salmonella pullorum $8.9 \times 10^{13}$ $\mathrm{CFU} / \mathrm{ml}$ contain $\mathrm{LD}_{50}$ dose in mice.

\section{Experimental immunization of chicken}

Experimental chickens were divided equally into three groups; Shuvra-A, Shuvra-B and Shuvra-C. The chickens in group Shuvra-A $(n=20)$ were vaccinated with $0.5 \mathrm{ml}\left(4.7 \times 10^{7} \mathrm{CFU} / \mathrm{ml}\right)$ of experimentally prepared BAU Salmonella bivalent vaccine. Similarly, group Shuvra-B $(\mathrm{n}=20)$ were vaccinated with $0.5 \mathrm{ml}$ $\left(2.43 \times 10^{8} \mathrm{CFU} / \mathrm{ml}\right)$ of BAU Fowl cholera vaccine while the remaining non-immunized was kept as control group Shuvra-C $(n=20)$. The initial dose (primary vaccination) of Salmonella bivalent and Fowl cholera vaccine were given to the birds of Shuvra-A and Shuvra-B respectively through IM route at the age of 8 weeks. These birds were revaccinated with same dose of vaccines through IM after four weeks of primary vaccination as booster (12 wks of age).

\section{Collection and preservation of sera}

The collection and preservation of sera were accomplished according to the method described by Heddleston and Reisinger (1960). The sera samples were collected on day 56 (8 weeks), 85 (12 weeks), 105 days (15 weeks) and after challenge at 140 days ( 20 weeks) age of the experimental birds. Sera was also collected from the control birds at 8,12 and 15 weeks of age and all the sera were kept in sterilized glass vials with rubber cap, raped with para film and preserved at $-20^{\circ} \mathrm{C}$ until used.

\section{Challenge exposure to the vaccinated chicken}

Test group of Shuvra-A, Shuvra-B and control group Shuvra-C were used for the protection test. After 7 days of final immunization the chickens of Shuvra-A were challenged with $\mathrm{LD}_{50}$ of $S$. gallinarum and $S$. pullorum $\left(8.9 \times 10^{13} \mathrm{CFU} / \mathrm{ml}\right.$ of $S$. gallinarum and $8.6 \times 10^{13} \mathrm{CFU} / \mathrm{ml}$ of $S$. pullorum) and chickens of Shuvra-B were challenged with $\mathrm{LD}_{50}$ of $P$. multocida $(250 \mu \mathrm{1}$ containing $2.43 \times 10^{8} \mathrm{CFU} / \mathrm{ml}$ ). Death pattern was observed upto 10 days.

\section{Passive haemagglutination (PHA) test}

The serological analysis was conducted by passive haemagglutination (PHA) test to determine antibody titres of the sera collected from both vaccinated and non vaccinated chickens following the method described by Tripathy et al. (1970).

\section{Statistical analysis}

The antibody titers of vaccinated and control birds were analyzed by students $t$ - test. Significance of survival rates of chicken were analyzed by Mantel Cox log rank test.

\section{Results}

The prevaccination mean PHA titre was $\leq 4.0 \pm 0.00$ in chickens of all groups (both vaccinated and unvaccinated). Each group contain 20 birds. Chickens of group Shuvra-A were vaccinated with BAU Salmonella bivalent $(\mathrm{SP}+\mathrm{SG})$ vaccine and Shuvra-B were vaccinated with BAU Fowl cholera vaccine at day 56 (primary vaccination) and then at 85 days of age (secondary vaccination). The sera samples were collected at day 56 (8 weeks), 85 (12 weeks), 105 (15 weeks) and after challenge at 140 (20 weeks) days age of birds for conducting PHA test

Results of passive haemagglutination assay (PHA) in chicken The prevaccination mean PHA titre was $\leq 4.0 \pm 0.00$ in chickens of all groups (both vaccinated and unvaccinated). In Shuvra-A, The mean PHA test conducted with both $S$. gallinarum and $S$. pullorum antigen revealed titre of $89.60 \pm 15.677$ and $89.60 \pm 15.677$ on 29 days of post primary vaccination, $153.60 \pm 25.60$ and $140.80 \pm 31.353$ on $20 \mathrm{DSV}, 140.80 \pm 31.353$ and $128.00 \pm 35.054$ on 55DSV (after challenge) (Table 1 and Fig. 1). In Shuvra-B, the mean PHA test performed with Fowl cholera vaccine expressed titre was $70.4 \pm 15.677$ on $29 \mathrm{DPV}$, $153.60 \pm 25.60$ on $20 \mathrm{DSV}$ and $140.80 \pm 31.353$ on $55 \mathrm{DSV}$ (after challenge) (Table 1 and Fig. 2).

Table 1. Results of mean PHA titre with standard error of sera of BLRI strain Shuvra-A and Shuvra-B chickens vaccinated with BAU Salmonella bivalent and BAU Fowl cholera vaccines

\begin{tabular}{|c|c|c|c|c|c|c|c|}
\hline $\begin{array}{c}\text { Weeks of } \\
\text { vaccination }\end{array}$ & $\begin{array}{c}\text { Pre-vaccinated } \\
\text { Antibody titre of all } \\
\text { vaccinated and } \\
\text { control (UVC) } \\
\text { Birds, (Mean } \pm \text { SE) }\end{array}$ & $\begin{array}{c}\text { Shuvra-A strains of } \\
\text { chicken vaccinated } \\
\text { with Salmonella } \\
\text { bivalent }(\mathrm{SP}+\mathrm{SG}) \\
\text { vaccine (Mean } \pm \text { SE) }\end{array}$ & $\begin{array}{c}\text { Level of } \\
\text { significance, } \\
\text { when compared } \\
\text { with control }\end{array}$ & $\begin{array}{l}\text { Shuvra-B strains of } \\
\text { chicken vaccinated } \\
\text { with Fowl cholera } \\
\text { Vaccine (Mean } \pm \text { SE) }\end{array}$ & $\begin{array}{c}\text { Level of } \\
\text { significance, } \\
\text { when compared } \\
\text { with control }\end{array}$ & \multicolumn{2}{|c|}{ Age of vaccination } \\
\hline \multirow{2}{*}{$\begin{array}{l}12 \text { weeks } \\
\text { (29 DPV) }\end{array}$} & \multirow{2}{*}{$\leq 4 \pm 0.00$} & $\begin{array}{l}\text { S. gallinarum, } \\
89.60 \pm 15.677\end{array}$ & $* *$ & \multirow{2}{*}{$70.4 \pm 15.677$} & \multirow{2}{*}{$*$} & \multirow[b]{2}{*}{$1^{\text {st }}$ dose } & \multirow[b]{2}{*}{$2^{\text {nd }}$ dose } \\
\hline & & $\begin{array}{c}\text { S. pullorum, } \\
89.60 \pm 15.677\end{array}$ & $* *$ & & & & \\
\hline \multirow{2}{*}{$\begin{array}{l}15 \text { weeks } \\
\text { ( } 20 \mathrm{DSV})\end{array}$} & \multirow{2}{*}{$\leq 4 \pm 0.00$} & $\begin{array}{l}\text { S. gallinarum, } \\
153.60 \pm 25.60\end{array}$ & $* *$ & \multirow{2}{*}{$153.60 \pm 25.60$} & \multirow{2}{*}{$*$} & \multirow{4}{*}{$\begin{array}{c}8 \text { weeks } / \\
56 \text { days }\end{array}$} & \multirow{4}{*}{$\begin{array}{c}12 \text { weeks } \\
85 \text { days }\end{array}$} \\
\hline & & $\begin{array}{c}\text { S. pullorum, } \\
140.80 \pm 31.353\end{array}$ & $*$ & & & & \\
\hline \multirow{2}{*}{$\begin{array}{l}20 \text { weeks } \\
\text { (55 DSV) }\end{array}$} & \multirow{2}{*}{$\leq 4 \pm 0.00$} & $\begin{array}{c}\text { S.gallinarum, } \\
140.80 \pm 31.353\end{array}$ & $*$ & \multirow{2}{*}{$140.80 \pm 31.353$} & \multirow{2}{*}{$*$} & & \\
\hline & & $\begin{array}{c}\text { S. pullorum, } \\
128.00 \pm 35.054\end{array}$ & $*$ & & & & \\
\hline
\end{tabular}

Vaccinated chickens were immunized at 8 weeks of age and boosted at 12 weeks of age via I/M route at the dose rate of $0.5 \mathrm{ml}$ of Salmonella bivalent: $4.7 \times 10^{7} \mathrm{CFU} / \mathrm{ml}$ and Fowl cholera: $2.43 \times 10^{8} \mathrm{CFU} / \mathrm{ml}$ in birds respectively. Blood was drawn at $8,12,15$ and 20 weeks (after challenge) of age. Serum antibody titre was determined by PHA test. The result is expressed as mean \pm SE values $(n=5)$. $* *=$ indicates significant at $1 \%$ level of significance $(\mathrm{P}<0.01) ; *$ indicates significant at $5 \%$ level of significance $(\mathrm{P}<0.05)$ 


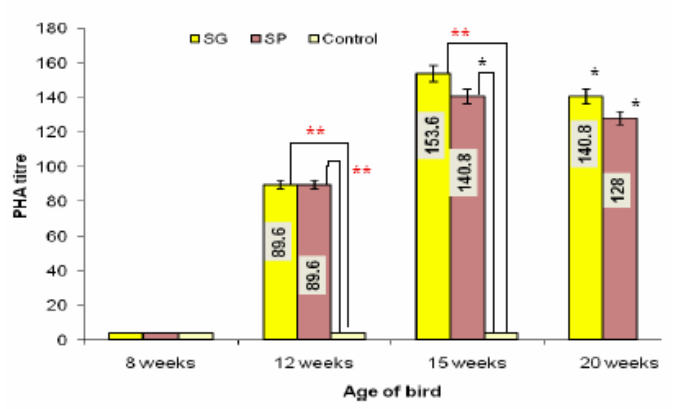

Fig. 1. Histogram showing of PHA titre (mean \pm SE) of sera of Shuvra-A chicken vaccinated with BAU Salmonella bivalent vaccine. Shuvra-A chicken was immunized at 8 weeks age and boosted at 12 weeks via $\mathrm{I} / \mathrm{M}$ route at the dose rate of $0.5 \mathrm{ml} / \mathrm{bird}$ $\left(4.7 \times 10^{7} \mathrm{CFU} / \mathrm{ml}\right)$. Blood was drawn at $8,12,15$ and 20 weeks (after challenge) of age. Serum antibody titre was determined by PHA test. The result is expressed as mean \pm SE $(n=10$ chicken/group). $\mathrm{P}$ value is determined by Student's t-test. $* *=P<0.01, *=P<0.05$

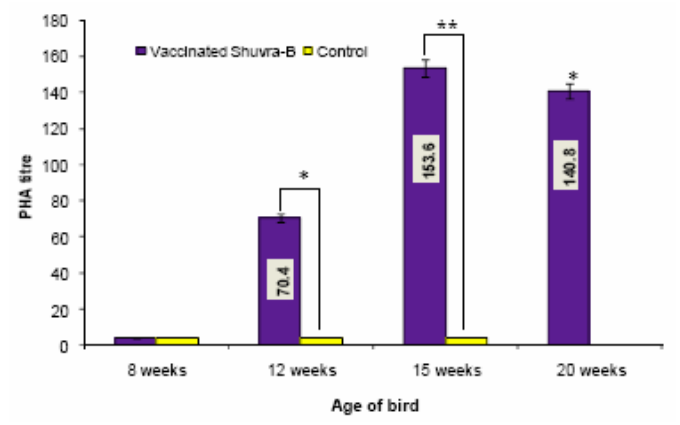

Fig. 2. Histogram showing PHA titre (mean \pm SE) of sera of Shuvra-B chicken vaccinated with BAU Fowl cholera vaccine. Shuvra-B chicken was immunized at 8 weeks age and boosted at 12 weeks via I/M route at the dose rate of $0.5 \mathrm{ml} /$ bird $\left(2.43 \times 10^{8}\right.$ $\mathrm{CFU} / \mathrm{ml}$ ). Blood was drawn at $8,12,15$ and 20 weeks (after challenge) of age. Serum antibody titre was determined by PHA test. The result is expressed as mean $\pm \mathrm{SE}$ ( $\mathrm{n}=10$ chicken/group). $\mathrm{P}$ is determined by Student's t-test. $* *=P<0.01, *=P<0.05$.

Survivability at challenge experiment

In post-challenge period, mortality rate was monitored for subsequent 10 days. Control group (Shuvra- C) died within 7 days where all the other vaccinated birds survived and conferred $100 \%$ protection against challenge infection (Fig. 3 and 4 ).

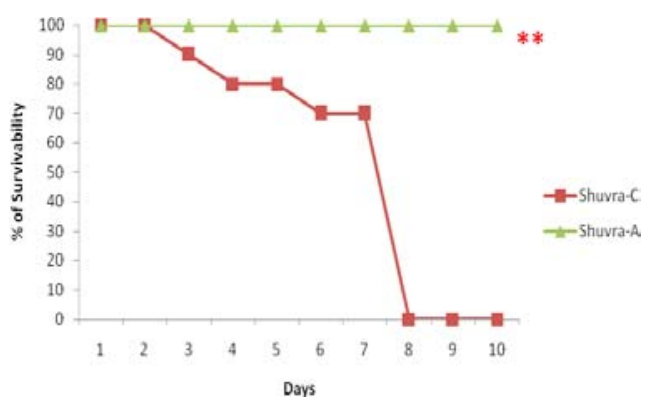

Fig. 3. Survival rate of Shuvra-A chicken challenged intramuscularly with virulent isolate of $S$. gallinarum and $S$. pullorum. Chickens were immunized twice with Salmonella bivalent vaccine at 8 week and boosted at 12 week of age of birds through $\mathrm{i} / \mathrm{m}$ route at the dose rate of $0.5 \mathrm{ml} /$ bird $\left(4.7 \times 10^{7} \mathrm{CFU} /\right.$ $\mathrm{ml})$. Control chickens were injected twice with $0.5 \mathrm{ml} \mathrm{PBS} / \mathrm{bird}$.
Survival rate of chicken was monitored following $\mathrm{i} / \mathrm{m}$ challenge with $\mathrm{LD}_{50}$ dose $(250 \mu \mathrm{l})$ of mice. The survival rate was monitored for subsequent 10 days. ( $\mathrm{n}=10$ chicken per group). $* *=P<0.01$ by Mantel-Cox Log rank test.

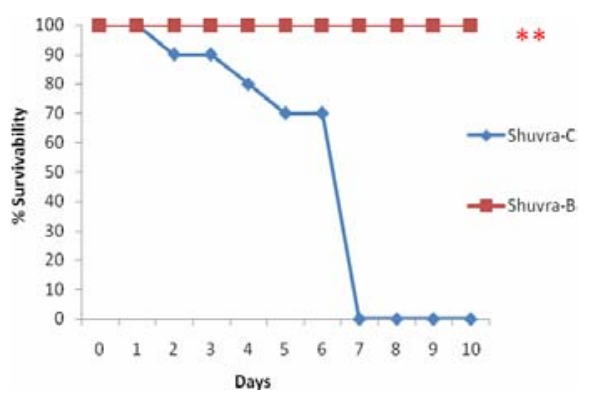

Fig. 4. Survival rate of Shuvra-B chicken challenged intramuscularly with virulent isolate of $P$. multocida. Chickens were immunized twice with BAU-FCV at 8 week and boosted at 12 week of age of birds through $\mathrm{i} / \mathrm{m}$ route at the dose rate of 0.5 $\mathrm{ml} /$ bird $\left(2.43 \times 10^{8} \mathrm{CFU} / \mathrm{ml}\right)$. Control chickens were injected twice with $0.5 \mathrm{ml} \mathrm{PBS} /$ bird. Survival rate of chicken was monitored following $\mathrm{i} / \mathrm{m}$ challenge with $\mathrm{LD}_{50}$ dose $(250 \mu \mathrm{l})$ of mice. The survival rate was monitored for subsequent 10 days. $(n=10$ chicken per group). ${ }^{* *}=P<0.01$ by Mantel-Cox Log rank test.

\section{Results of challenge exposure}

Challenge infection at the dose rate of $1 \mathrm{ml}(S$. pullorum: $8.6 \mathrm{x}$ $10^{13} \mathrm{CFU} / \mathrm{ml}, S$. gallinarum: $8.9 \times 10^{13} \mathrm{CFU} / \mathrm{ml}$ and $P$. multocida: $2.43 \times 10^{8} \mathrm{CFU} / \mathrm{ml}$ ) was given to the vaccinated and unvaccinated chickens. All the vaccinated birds (Shuvra-A, Shuvra-B) were refractory to virulent challenge exposure showing alertness and were physically healthy. Birds of the control group Shuvra-C showed sign and symptoms of infection within 1-2 days of challenge infection.

\section{Discussion}

The present study was undertaken to determine the efficacy of BAU Salmonella bivalent and BAU Fowl cholera vaccines produced at LPVRPC, BAU, Mymensingh. As an essential part of efficacy test, the $\mathrm{LD}_{50}$ of virulent Salmonella gallinarum, Salmonella pullorum and Pasteurella multocida was also determined individually in this study. During preparation of two types of vaccines, sterility and safety tests were individually carried out as per recommendation for OIE (2008). The prevaccinated PHA titre of sera samples of all BAU Salmonella bivalent and BAU Fowl cholera vaccinated chickens were recorded as $\leq 4 \pm 00$ which was closely related to the findings of Ferdous (2008), Khatun (2011) and Mondal et al. (1988).

In Shuvra-A, the mean PHA antibody titre on day 85 (29 DPV) was recorded as $89.60 \pm 15.677$ with $S$. gallinarum antigen and $89.60 \pm 15.677$ with $S$. pullorum antigen respectively. Following vaccination with BAU Fowl cholera the mean PHA titre at same days $70.4 \pm 15.677$, incase of Shuvra-B chicken. Subsequent secondary (booster dose) vaccination in Shuvra-A chicken, the mean PHA titre $153.60 \pm 25.60$ with $S$. gallinarum antigen and $140.80 \pm 31.353$ with $S$. pullorum respectively. On similar period, the mean PHA titre of birds having BAU-FCV vaccine ascended to $153.60 \pm 25.60$ in sera samples obtained from Shuvra-B group of chickens. In case of challenge experiment conducted at 55 days of secondary vaccination, in Shuvra-A, the serum mean PHA titre of $140.80 \pm 31.353$ with $S$. gallinarum and $128.00 \pm 35.054$ with $S$. pullorum antigen. Similarly, sera samples from Shuvra-B having BAU Fowl cholera vaccine, the serum mean PHA titre was $140.80 \pm 31.353$. Thus, an overall review reflected a significant level of PHA titre following secondary (booster) vaccination at 12 weeks produced better immune response $(\mathrm{P}<.05)$ and showed a highest Mean $\pm \mathrm{SE}$ titre. 
Chickens of both the groups (vaccinated and control) were challenged with virulent field isolate of $S$. pullorum: $\left(8.6 \times 10^{13}\right.$ $\mathrm{CFU} / \mathrm{ml})$ and $S$. gallinarum: $\left(8.9 \times 10^{13} \mathrm{CFU} / \mathrm{ml}\right)$ and $P$. multocida $\left(2.43 \times 10^{8} \mathrm{CFU} / \mathrm{ml}\right)$ with dose rate $250 \mu 1 \mathrm{LD}_{50}$ of mice. It was observed that all the vaccinated birds were $100 \%$ resistant to virulent challenge exposure. Birds of the control group showed signs of disease within 1 days of challenge and all of them died within 7 days.

It may be noted that, newly developed Shuvra strain of chicken was for the first time exposed to field vaccine. However, the study would have been more appreciable if the study be performed with further details.

\section{Conclusion}

It was demonstrated that immunogenicity of both the vaccines used in Shuvra strain of chicken was dependable and a protection of $100 \%$ was observed and the vaccines were safe.

\section{References}

Aklilu HA, Udo HMJ, Almekinders CJM and Van der Zijpp AJ, 2008. How resource poor households value and access poultry: Village poultry keeping in Tigray, Ethiopia. Agric. Syst, 96: 175-183.

Boyce JD and Adler B, 2006. How does P. multocida respond to the host environment. Curr Opin Microbiol, 9: 117-122.

Barrow PA and Freitas NOC, 2011. Pullorum disease and fowl typhoid - new thoughts on old diseases: a review. Avian Pathol., 401: 1-13.

Buxton A and Fraser G, 1977. Blackwell Scientific Publications, Oxford, London, Edinburg, Melbourne. Animal Microbiology, 1: 85-86.

Choudhyury KA, Amin MM, Rahman A, and Ali MR, 1985 Investigation of natural outbreaks of fowl typhoid. Bangladesh Veterinary Journal. 19: 49-56.

Davies RH, Carrique JJ, Morris V, Harrison D, Tucker V, and Allen VM, 2010. Effect of delivery method on the efficacy of Salmonella vaccination in chickens, 167: 161-4.

DLS, 2011. Annual report of Department of Livestock Services, Khamarbari Road, Farmgate, Dhaka.

Ferdous, J, 2008. Immunogenicity study of DLS prepared Salmonella gallinarum vaccine in comparison to commercially available one in layer chicken. M.S. Thesis submitted to the Department of Microbiology and Hygiene, Faculty of Veterinary Sciences, Bangladesh Agricultural University, Mymensingh, 38-45.

Heddleston KL and Reisinger RC, 1960. Studies on Salmonellosis. IV. Killed fowl typhoid vaccine absorbed on aluminium hydroxide. Avian Disease, 4: 429-435.

Khan MAHNA, Islam MR, Das PM and Ali MY, 1998. Pullorum disease in semi mature chickens and its experimental pathology. Bang. Vet. J, 32: 124-128.

Khatun R, 2011. Investigation on the efficacy of Salmoonella gallinarum killed vaccine. M.S. Thesis submitted to the Department of Microbiology and Hygiene, Faculty of Veterinary Sciences, Bangladesh Agricultural University, Mymensingh, 38-45.

Klein E, 1889. Uber eine epidemische Krankheit der Huhner, Verursachtdurch einer Bacillus-Bakteriol Parasitenkol. Vet. Bullt, 5: 689-693

Mondal SK, Choudhury KA, Amin MM, Rahman MM and Sarker AJ, 1988. Immune response in chickens induced by Alum precipitated fowl cholera vaccine. I. Humoral immune response. Bang. Vet. J, $22: 3-4$.

(OIE) Office International des Epizooties, 2008. Manual of Standards for Diagnostics Tests and Vaccines. $6^{\text {th }}$ edition.

Rettger LF, 1900. Septicemia among young chickens. New York Medical Journal, 71: 303-895.

Shivaprasad HL and Barrow PA, 2008. Pullorum disease and fowl typhoid. In Y.M Saif, A.M. Fadley, J.R Glisson, L.R. McDougald, L.K. Nolan, D.E Swayne (Ed.). Diseases of Poultry 12th edn, 620-634. Ames: Iowa State Press.

Kottwitz LBM, Oliveira TCRM, Alcocer I, Farah SMSS, Abrahão WSM and Rodrigues DP, 2010. Avaliação epidemiológica de surtos de salmoneloses ocorridos no período de 1999 a 2008 no Estado do Paraná, Brasil. Acta Scientiarum Health Sciences, 32: 9-15.

Tripathy DN, Hanson LE and Mysers WL, 1970. Passive haemagglutination test with fowl pox virus. Avian Diseases, 14: 29-38. 